\title{
Knowledge, attitude, and practice about HIV/AIDS among men who have sex with men in Belgaum: A cross-sectional study
}

$\pi$
0
0
0
5
0
$\frac{\pi}{4}$

Santosh Patil, Vijaya Ashok Naik', Ashwini Basavagouda Narasannavar ${ }^{1}$, Bijendra Banjade', Ashutosh Shrestha ${ }^{1}$

District Epidemiologist, IDSP, Sangli, Maharashtra, 'Department of Public Health,

J.N. Medical College, KLE University, Belgaum, Karnataka, India

Address for the Correspondence:

Dr. Ashwini B Narasannavar, Lecturer, Department of Public Health, J.N. Medical College, KLE University, Belgaum, Karnataka, India E-mail: drashwinimph2004@ gmail.com

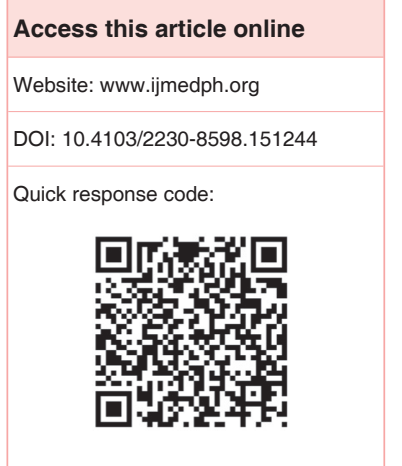

Background: AIDS epidemic is major public health emergency and young people are bearing the main brunt of the new infection worldwide. MSM constitute a high risk group for sexually transmitted infections including HIV in many parts of the world. Objectives: To assess knowledge, attitude of HIV/AIDS and sexual practices among MSM residing in city of Belgaum. Methodology: Cross sectional study was conducted at Sweekar NGO for MSM. Based on the Sampling Procedure and inclusion Criteria $50 \%$ of MSM were selected for the study. Therefore the sample size for this study was 416. Data collection was done using pre-designed and pre-tested questionnaire. Results: A total of $416 \mathrm{MSM}$ were interviewed by the trained peer workers. Majority of them (27.64\%) were in 25-30 years of age. Majority of them had good knowledge of modes of transmission of $\operatorname{HIV}(90.38 \%)$, its prevention $(98.09 \%)$, availability of treatment $(89.66 \%) .61 .30 \%$ were having good knowledge of symptoms. Friend was the first sexual partner for $67.89 \%$ participants. Half of the participants were performing both anal and oral form sex. Conclusion: Although the knowledge of modes of transmission, symptoms, investigations, treatment and prevention of HIV/AIDS has been good among the MSM but prevention was not been practiced by most. NGOs working with MSM need to organize some interventions aimed at changing the harmful sexual practices into healthy practices.

Key words: Condom use, HIV/AIDS, homosexual, knowledge, attitude and practice

\section{INTRODUCTION}

HIV/AIDS is one of the emerging infectious diseases all over the world. It has evolved from a mysterious illness to a global pandemic, which has infected tens of millions in $>20$ years. ${ }^{[1]}$

It is estimated that there are 12.63 lakh female sex workers (FSW), 3.5 lakh men who have sex with men (MSM) with high-risk behavior and 1.86 lakh injecting drug users in India. Based on these data unprotected sex $(87.4 \%$ heterosexual and $1.3 \%$ homosexual $)$ is the major route of HIV transmission, followed by transmission from Parent to Child (5.4\%) and use of infected blood and blood products $(1.0 \%) \cdot{ }^{[2]}$

Men who have sex with men are a vulnerable population and need special attention in the fight against the global pandemic of HIV/AIDS. ${ }^{[3]}$ MSM constitute a high risk group for sexually transmitted infections including HIV in many parts of the world. Data on MSM are not routinely collected in India because of taboo, prohibition by law and often not recognized. Despite these restrictions MSM are prevalent in India. A better understanding of this group is required. ${ }^{[3]}$

As per the 2007 estimate HIV prevalence in MSM in Karnataka was about $17.60 \% .{ }^{[4]}$ MSM population is visible in some countries, but in India MSM are much less visible because they fear discrimination, stigmatization (being considerable socially unacceptable) or sex between men is illegal in India like other 85 countries. MSM are often under-represented in HIV surveillance systems and in prevention and care programs. ${ }^{[5,6]}$ To halt the epidemic of HIV/AIDS, it is necessary to understand the prevalence of disease in MSM. ${ }^{[6]}$ There are no similar studies carried out among MSM in the region of north Karnataka. This study is aimed to find out knowledge, attitude toward HIV/AIDS and sexual practices 
among MSM. Study of this kind will help to develop strategies to prevent the spread of HIV/AIDS among MSM.

\section{MATERIALS AND METHODS}

This was an observational descriptive study, conducted over a period of 10 months, March-December 2011. Among all MSM of age group 18 years to 40 years who had registered in MSM's Sweekar — Nongovernmental organization (NGO) at Belgaum city that is the only NGO for MSM. About 800 members of different age groups were registered in Sweekar NGO. Based on systematic random sampling every alternate participant was selected; thus, the sample size became 416. Ethical clearance was obtained from Institutional Ethics Committee.

Predesigned, pretested structured proforma was used to collect informations pretesting of the study proforma was carried out before starting the main study. Necessary changes were made in proforma based on pretesting. Information was collected on knowledge, attitude and practices toward HIV/AIDS, its causes, modes of spread, prevention, use of condom, etc. Information was also collected regarding demographic and socioeconomic characteristics of the study participants. All three peer counselors of Sweekar NGO were trained by the investigator to collect the information required to complete the questionnaire. Half day (3-4 h) training was given by the investigator to the peer workers. Peer workers also obtained the written informed consent before commencing the data collection. Information was collected by one-to-one conversation by peer counselor and the confidentiality was maintained.

Men aged between 18 and 40 years who were registered in Sweekar NGO and who had sex with men within past 12 months were included in the study. Transgender were excluded from the study. Data were entered into Microsoft Excel and percentages were calculated for every variable.

\section{RESULTS}

Out of 416 participants $27.64 \%$ were in 25-30 years of age. $41.59 \%$ were having their own business (pan shop, plastic utensil shop etc.), $1.44 \%$ was unemployed (who are not involved in the income generating activities for $>6$ months, but actively searching for a job) and about 7\% were students involved in MSM activity. $13.22 \%$ were illiterate (a person can be considered literate if he/she can read and write with understanding in any language and he/she should be above 7 years of age) and rest were literate. More than $60 \%$ belonged to socioeconomic status classes IV and V (as per Modified B.G Prasad classification-2010). Of the total 141 were un-married, and most of them $(82.45 \%)$ belonged to Hindu religion.

Table 1 revealed the knowledge of MSM regarding various aspects of HIV/AIDS. Majority of them had good knowledge of modes of transmission of HIV $(90.38 \%)$, its prevention (98.09\%), curability $(97.36 \%)$, availability of treatment $(89.66 \%)$.

\begin{tabular}{|c|c|c|}
\hline Knowledge regarding HIVIAIDS & Number $(n)$ & Percentage \\
\hline \multicolumn{3}{|l|}{ Modes of transmission } \\
\hline Good (all correct answers) & 377 & 90.63 \\
\hline Average (at least $50 \%$ correct answers) & 35 & 8.41 \\
\hline Poor (<50\% correct answer) & 04 & 0.96 \\
\hline \multicolumn{3}{|l|}{ Knowledge of symptoms } \\
\hline Good (all correct answers) & 255 & 61.30 \\
\hline Average (at least $50 \%$ correct answers) & 86 & 20.67 \\
\hline Poor $(<50 \%$ correct answer $)$ & 52 & 12.50 \\
\hline No knowledge (no answer) & 23 & 5.53 \\
\hline \multicolumn{3}{|l|}{ Spread of diseases through MSM act } \\
\hline STD & 17 & 4.09 \\
\hline HIVIAIDS & 124 & 29.81 \\
\hline Both (HIV and STD) & 235 & 56.49 \\
\hline Doesn't spread & 40 & 9.62 \\
\hline \multicolumn{3}{|l|}{ Laboratory investigation } \\
\hline Aware & 414 & 99.52 \\
\hline Not aware & 02 & 0.48 \\
\hline \multicolumn{3}{|l|}{ Treatment } \\
\hline Available & 373 & 89.66 \\
\hline Not available & 43 & 10.34 \\
\hline \multicolumn{3}{|l|}{ Contagiousness of HIVIAIDS } \\
\hline Contagious & 06 & 1.44 \\
\hline Not contagious & 410 & 98.56 \\
\hline \multicolumn{3}{|l|}{ Cure of disease } \\
\hline Can be cured & 11 & 2.64 \\
\hline Cannot be cured & 405 & 97.36 \\
\hline \multicolumn{3}{|l|}{ Prevention } \\
\hline Aware & 410 & 98.56 \\
\hline Not aware & 06 & 1.44 \\
\hline
\end{tabular}

MSM = Men who have sex with men, STD = Sexually transmitted diseases

Laboratory investigations (99.52\%), symptoms (61.30\%) and contagiousness $(98.56 \%)$. However, $9.61 \%$ were not aware of the fact that HIV and sexually transmitted diseases (STD) spread by MSM act. The main source of information was health workers for $42.55 \%$

It was found from Table 2 that majority of them $(97.60 \%)$ were sympathetic towards HIV/AIDS patient and almost all were against the removal of HIV/AIDS patient from job. $15.87 \%$ of the participants thought that it was not necessary to know the HIV status of their new partner. Majority of them said that MSM should be legalized.

Table 3 shows sexual practices of the study population. $56.49 \%$ of them had multiple partners. The age at first sexual intercourse was found to be between 10 and 15 age groups among 68\% MSM. Friend was the first sexual partner for $67.89 \%$ participants. Majority of the married participants were not using a condom with their wives (94.18\%) and FSW (72.97\%) though they were using a condom with their male partner (99.28\%). Half of the participants were performing both anal and oral form of sexes. $52.50 \%$ had either one or other habit. 


\begin{tabular}{|c|c|c|}
\hline Attitude & Number $(n)$ & Percentage \\
\hline \multicolumn{3}{|c|}{ Sympathy towards HIVIAIDS patient } \\
\hline Sympathetic & 406 & 97.60 \\
\hline Not sympathetic & 10 & 2.40 \\
\hline \multicolumn{3}{|c|}{ Removal of HIVIAIDS patient from job } \\
\hline Should remove & 02 & 0.48 \\
\hline Should not remove & 414 & 99.52 \\
\hline \multicolumn{3}{|c|}{$\begin{array}{l}\text { Willingness to know the HIV status of } \\
\text { new partner }\end{array}$} \\
\hline Wants to know & 350 & 84.13 \\
\hline Doesn't want to know & 66 & 15.87 \\
\hline \multicolumn{3}{|c|}{ Marriage of HIV infected person } \\
\hline With infected person & 121 & 29.09 \\
\hline With noninfected person & 03 & 0.72 \\
\hline Should not marry & 292 & 70.19 \\
\hline \multicolumn{3}{|c|}{ Whether to have children $(n=124)$} \\
\hline Should have children & 57 & 45.97 \\
\hline Should not have children & 67 & 54.03 \\
\hline \multicolumn{3}{|l|}{ Legalisation of MSM } \\
\hline Should be legalised & 410 & 98.56 \\
\hline Should not be & 06 & 1.44 \\
\hline
\end{tabular}

MSM = Men who have sex with men, STD = Sexually transmitted diseases

\section{DISCUSSION}

In the present study, slightly more than the quarters were in the age group of 25-30 years. As against this the age range of MSM was 16-65 years with a median of 27 years in Andhra Pradesh study. ${ }^{[7]}$ In the South Indian study majority of MSM were in the age group of 18-24 years; highest being from Maharashtra. ${ }^{[4]}$ In Kolkata study, the mean age of the participants was 22.1 years. ${ }^{[5]}$ The Hong Kong study revealed that majority of the participants (43\%) were below 30 years. ${ }^{[6]}$ It appeared that the age group of $20-25$ years is the most common age for MSM behavior. Perhaps this age group is not aware of hazards of MSM act.

In the present study majority of the participants $173(41.59 \%)$ were having their own business, About 33.89\% were engaged in various kinds of work involving daily wages. Thus, the majority of people were from the category where in every day brings out challenging situation with respect to income and other comforts of life forcing the individual to go for alternative modes of getting pleasure. Almost $7 \%$ MSM were students. As against this; in Kolkata study almost 3 times of the study population were students. ${ }^{[8]}$ At the tender age of teenage, the students are exposing themselves to abnormal sexual behavior without realizing the risks involved in it. In Mumbai study, $34 \%$ were skilled and $22 \%$ unskilled laborers. ${ }^{[8]}$ In Kolkata study $22.2 \%$ were drivers, $11.1 \%$ were businessmen, and $15.7 \%$ were professionals. ${ }^{[5]}$ In our study, $1.44 \%$ were unemployed. As against this in Kolkata study more than double (4.6\%) were unemployed. ${ }^{[5]}$ Kolkata being metropolitan city majority were migrants.

In our study, majority of them $(90.38 \%)$ were literate among whom $145(34.86 \%)$ studied up to college or above. It was noted that 40

\begin{tabular}{|c|c|c|c|c|}
\hline Sexual practices & & Number $(n)$ & \multicolumn{2}{|c|}{ Percentage } \\
\hline \multicolumn{5}{|l|}{ Sexual partners } \\
\hline More than one & & 235 & \multicolumn{2}{|c|}{56.49} \\
\hline Single/one & & 181 & \multicolumn{2}{|c|}{43.51} \\
\hline \multicolumn{5}{|l|}{ Age at first sexual act } \\
\hline Below 10 & & 19 & \multicolumn{2}{|c|}{4.57} \\
\hline $10-15$ & & 284 & \multicolumn{2}{|c|}{68.27} \\
\hline $15-20$ & & 109 & \multicolumn{2}{|c|}{26.20} \\
\hline 20 and above & & 4 & \multicolumn{2}{|c|}{0.96} \\
\hline \multicolumn{5}{|l|}{ First sexual partner } \\
\hline Friend & & 282 & \multicolumn{2}{|c|}{67.79} \\
\hline Neighbor & & 22 & \multicolumn{2}{|c|}{5.29} \\
\hline Family member & & 62 & \multicolumn{2}{|c|}{14.90} \\
\hline Strangers & & 21 & \multicolumn{2}{|c|}{5.05} \\
\hline Others & & 29 & \multicolumn{2}{|c|}{6.97} \\
\hline \multicolumn{5}{|l|}{ Sexual activity } \\
\hline Oral & & 58 & \multicolumn{2}{|c|}{13.94} \\
\hline Anal & & 129 & \multicolumn{2}{|c|}{31.01} \\
\hline Both & & 229 & \multicolumn{2}{|c|}{55.05} \\
\hline \multicolumn{5}{|l|}{ Habits } \\
\hline No habit & & 156 & \multicolumn{2}{|c|}{37.50} \\
\hline Smoking & & 5 & \multicolumn{2}{|c|}{1.20} \\
\hline Alcohol consumption & & 70 & \multicolumn{2}{|c|}{16.83} \\
\hline Guthakha & & 16 & \multicolumn{2}{|c|}{3.85} \\
\hline Tobacco chewing & & 19 & \multicolumn{2}{|c|}{4.57} \\
\hline Multiple habits & & 150 & \multicolumn{2}{|c|}{36.06} \\
\hline Condom users & Users & Nonusers & Users & Nonusers \\
\hline $\begin{array}{l}\text { By married MSM with } \\
\text { FSW }(n=37)\end{array}$ & 10 & 27 & 27.03 & 72.97 \\
\hline With wife $(n=275)$ & 16 & 259 & 5.82 & 94.18 \\
\hline MSM with FSW $(n=78)$ & 19 & 59 & 24.36 & 75.64 \\
\hline With male partner $(n=416)$ & 413 & 3 & 99.28 & 0.72 \\
\hline
\end{tabular}

MSM = Men who have sex with men, FSW = Female sex workers

$(9.62 \%)$ participants were illiterates. Similar results were found in the study conducted in four states of South India with literates being $77.9 \%$ in Andhra Pradesh, 90.9\% in Maharashtra, 85.9\% in Tamil Nadu, and $78.2 \%$ in Karnataka. ${ }^{[4]}$ In Kolkata study $13.9 \%$ were illiterate and $1 / 4^{\text {th }}$ of MSM had completed secondary school. ${ }^{[5]}$ As per Sri Lankan study $1.8 \%$ never attended school, whereas $7.9 \%$ were graduate. ${ }^{[9]}$

In the present study, $>60 \%$ were from lower socioeconomic group (class IV [43.51\%] and class V [20.91\%]). These results are similar to Kolkata study where majority of the participants were from lower socioeconomic group. ${ }^{[5]}$

In our study, 141 (33.89\%) participants were unmarried and 275 $(66.11 \%)$ were married to a woman. It appears that the sexual behavior that was inculcated during teenage has continued after marriage of a man with a woman. This bisexual behavior of MSM will expose the married female partner to great risk of HIV/AIDS. In Andhra Pradesh study, $2.3 \%$ were currently married to a man in a private ceremony although marriage amongst same sex is not legally recognized in India. In this study, $3.7 \%$ were previously married to a man. Six percent were currently living with a male sex partner. About $41 \%$ were currently 
married to a woman. Almost 5\% were separated/divorced from woman and $1.3 \%$ were widowed. ${ }^{[7]}$ In Sri Lanka study majority of the $(60.3 \%)$ respondents were unmarried, whereas $9.3 \%$ were divorced and $6.3 \%$ of respondents were staying with male partners. ${ }^{[9]}$

In the present study, majority (90.63\%) of the participants had good knowledge about modes of transmission of HIV/AIDS. In Sri Lanka study $75 \%$ of MSM were aware of the modes of transmission of HIV/AIDS; ${ }^{[9]}$ in Vietnam study, it was $77 \% 0^{[10]}$ and in China study it was $86.6 \% \cdot{ }^{[1]}$

In our study, good knowledge of symptoms of HIV/AIDS was seen among $61.30 \%$ participants. Although this was comparable with the figure of Karnataka (67.3\%) it was low when compared with figures of other states like Andhra Pradesh, Maharashtra, Tamil Nadu where the figures ranged from $98.1 \%$ to $99.7 \%{ }^{[4]}$ In China study also the results were similar to that of our $(59.7 \%) .{ }^{[12]}$

About 56.49\% MSM believed that MSM act spreads HIV, as well as other STDs, 4\% believed that it spreads only STDs, and 29.81\% believed that it spreads only HIV/AIDS. South Indian study revealed similar results. ${ }^{[4]}$ Ninety percent of MSM of this study were aware of availability of treatment of HIV/AIDS. All of them were aware that it is available in a civil hospital. As opposite to this the South Indian study revealed that the knowledge of availability of treatment was very low ranging from $6 \%$ to $18 \%{ }^{[4]}$

Almost all participants of our study believed that HIV/ AIDS is not a contagious disease while $97.36 \%$ believed that there is no cure for HIV/AIDS. Ninety-nine percent of the participants believed that HIV/AIDS can be prevented. These were comparable with the results of South Indian study. ${ }^{[4]}$ In Sri Lanka study, $85 \%$ believed that the use of the condom prevents HIV/AIDS. ${ }^{[9]}$ Health workers have been the main source of information regarding HIV/AIDS for $42.55 \% \mathrm{MSM}$ in the present study. Other sources have been television, friends and newspapers In order to make an effective source of information regarding HIV/AIDS it is necessary to strengthen the mass media like television to play an important role with respect to prevention of HIV/AIDS., However in Sri Lankan study newspapers (80\%) and handbills (68.8\%) were the major sources of information. ${ }^{[9]}$ and in Mumbai study the main source of information was television (33\%), followed by doctors $(33 \%) .{ }^{[8]}$

Almost $98 \%$ of MSM were sympathetic towards HIV/AIDS patient. Almost all were against the removal of HIV/AIDS patient from job. About 16\% felt that there was no need of knowing the HIV status of their new partner $70 \%$ participants were of the attitude that HIV-infected person should not marry. About $46 \%$ of participants felt that HIV patient should have children. Majority of participants believed that MSM should be legalized (98.56\%). Similar findings were observed in Sri Lanka study. ${ }^{[9]}$

In the present study, majority (68.27\%) had the first MSM act in the age group of 10-15 years whereas in Kolkata study it was in the age group of 15-19 years. ${ }^{[5]}$ There have been some participants having first MSM act even before 10 years in our study as well as in Kolkata study ${ }^{[5]}$ highlighting the importance of sex education to primary school children. Mass media, especially television may be playing an important role for children $<15$ years to become curios regarding sexual activity. The South Indian study also revealed that majority of the MSM had first sexual contact during the adolescent period. ${ }^{[4]}$ In our study friend has been a partner in almost $67 \%$ of participants. Family member, neighbor and even stranger has been a partner for remaining. These results are consistent with the results of Kolkata study. ${ }^{[5]}$

In our study $18.75 \%$, MSM visited FSWs. As opposite to this in Mumbai study more than the double (44\%) of the MSM were visiting FSW. ${ }^{[7]}$

In Andhra Pradesh study, one-fourth had anal sex without a condom and $84 \%$ during vaginal sex also. ${ }^{[7]}$ In Kolkata study, only 15\% were using a condom during vaginal sex and $6 \%$ during anal sex. ${ }^{[5]}$ The low rate of condom use in this study was because of the fact that half of them felt that there is no need to use condom if the sexual partner was extremely attractive and if partner was clean and hygienic. The other reason was that anal sex is for fun. Hence condom should not be used. ${ }^{[5]}$ In China study, the use of a condom with MSM varied between $39.2 \%$ and $65.2 \%{ }^{[12]}$ In Beijing study $27.6 \%$ participants were always using a condom during vaginal and $36.4 \%$ during anal intercourse with women in the past 6 months, $40.1 \%$ MSM were always using a condom during active and $36.4 \%$ during receptive anal sex with men. ${ }^{[7]}$ In Vietnam study, 67\% MSM had ever used a condom, but only $32 \%$ used during their last sexual encounter. Forty percent MSM used condom at their last anal sex. Among those who had vaginal sex $56 \%$ used a condom. Condom use with clients during anal sex was higher but not consistent, with $42 \%$ usually or always using condoms, 33\% sometimes using condoms, and 25\% never using. ${ }^{[10]}$ Sri Lanka study revealed that 6.1\% MSM used condom every time and $5.9 \%$ never used during insertive anal sex while $6.6 \%$ were using a condom every time, $42.4 \%$ sometimes and $13.4 \%$ never used condom during receptive anal sex. ${ }^{[9]}$

In the present study, majority of (55.05\%) the participants practiced both anal and oral sexual activity with their partner while $31 \%$ participants practiced only anal sexual activity. Majority of them $(87.26 \%)$ were involved in bisexual activity while $12.74 \%$ were involved in homosexual activity. Majority of the participants had multiple sexual partners $(56.49 \%)$ highest being eight partners while $43.51 \%$ had single sexual partner. In Kolkata study the most common sexual act was receptive anal sex (83.3\%) followed by vaginal sex, oral sex and insertive anal sex. Seven percent were practicing both insertive and receptive form of sex. The study population mostly had multiple partners with $58.2 \%$ having $>1$ partner in the last 1 month. Even in $5.6 \%$ of the cases, the number of partners in the last 1 month was alarmingly high in the order of six or more. ${ }^{[8]}$ In Andhra Pradesh study, 63.7\% had anal sex with a man. About $45 \%$ had anal sex with $>1$ different man. ${ }^{[7]}$ In Zhejiang Province Study, $43.7 \%$ had multiple male sex partners, and half of them used 
condom every time when having anal intercourse with a man. ${ }^{[14]}$ In Sri Lanka study, 30\% of MSM were practicing anal insertive sex whereas $29.8 \%$ receptive anal sex and $36 \%$ were practicing both insertive as well as receptive anal sex..$^{[9]}$

In the present study, $1.20 \%$ participants were having the habit of smoking. The other habits were alcohol consumption (16.83\%), Guthakha (3.85\%), tobacco chewing (4.57\%). Majority of them 150 $(36.06 \%)$ had multiple habits. Among the alcohol drinkers majority $(85.99 \%)$ had sex under the influence of alcohol. This is in contrast to Vietnam study where alcohol use was as high as 66\%. While $15 \%$ reported usually or always drinking alcohol and 40\% sometimes reported drinking alcohol before or during sex.$^{[10]}$ In Sri Lanka study more than one-third of the men (35\%) used alcohol prior to having sex with other men. Among these, $13.3 \%$ used alcohol every time and $63 \%$ sometimes before having sex. $30 \%$ of them were using ganja (marijuana) and $2 \%$ were injecting drugs. ${ }^{\left[{ }^{[]}\right.}$

\section{CONCLUSION}

Almost all MSM had good knowledge about the modes of transmission, prevention, treatment, and had a positive attitude toward the HIV patients, but the same was not true with their sexual behavior. All had sympathy toward them. Many had $>1$ partner and were bisexual. Among married men although they had knowledge about condom they used it during the MSM act, but not with their wives thus putting them into risk for HIV/AIDS.

Nongovernmental organization needs to organize some interventional programs aimed at changing the harmful sexual practices of MSM. More information education and communication activities related to preventive measures should be done in these NGOs.

\section{ACKNOWLEDGMENT}

We thank all who supported directly and indirectly for the completion of research.

\section{REFERENCES}

1. Park K. Park's Textbook of Preventive and Social Medicine. $20^{\text {th }}$ ed. Jabalpur: Banarasidas Bhanot Publications; 2009. p. 298.

2. NACO. Current Epidemiological Situation of HIVIAIDS. NACO Annual Report 2010-11. Department of AIDS Control. Ch. 2. National AIDS Control Organisation, Ministry of Health \& Family Welfare, GOI; 2010-11. p. 6. Available from: http://www.nacoonline.org/Quick_Links/Publication/
Annual_Report/NACO_Annual_Report/NACO_Annual_Report_2011/. [Last accessed on 2012 July 23].

3. Gupta A, Mehta S, Godbole SV, Sahay S, Walshe L, Reynolds SJ, et al. Same-sex behavior and high rates of HIV among men attending sexually transmitted infection clinics in Pune, India (1993-2002). J Acquir Immune Defic Syndr 2006;43:483-90.

4. Brahmam GN, Kodavalla V, Rajkumar H, Rachakulla HK, Kallam S, Myakala SP, et al. Sexual practices, HIV and sexually transmitted infections among self-identified men who have sex with men in four high HIV prevalence states of India. AIDS 2008;22 Suppl 5:S45-57.

5. Deb S, Dutta S, Dasgupta A, Biswas B. Sexual Practice and Perception of HIVIAIDS Amongst Men who have Sex with Men in Kolkata. Indian J Community Med 2009;34:206-11.

6. Lau JT, Siah PC, Tsui HY. A study of the STD/AIDS related attitudes and behaviors of men who have sex with men in Hong Kong. Arch Sex Behav 2002;31:367-73.

7. Setia MS, Lindan C, Jerajani HR, Kumta S, Ekstrand M, Mathur M, et al. Men who have sex with men and transgenders in Mumbai, India: An emerging risk group for STIs and HIV. Indian J Dermatol Venereol Leprol 2006;72:425-31.

8. Ariyaratne KA, editor. Knowledge, Attitude and Practice in the Gay Community, Gay Identified Men, and Men Who have Sex with Men in Sri Lanka. Available from: http://www.aidscontrol.gov.Ik/nsacp/Web\%20uploads/ Research\%20Documents/COJ\%20Knowledge,\%20Attitude\%20and\%20 Practice\%20in\%20the\%20 gay $\% 20$ community,\%20 gay\%20identified $\% 20$ men,\%20and\%20Men\%20who\%20 have\%20Sex\%20with\%20 men\%20 in\%20Sri\%20 Lanka.pdf. [Last accessed on 2011 July 06].

9. Dandona L, Dandona R, Gutierrez JP, Kumar GA, McPherson S, Bertozzi $\mathrm{SM}$, et al. Sex behaviour of men who have sex with men and risk of HIV in Andhra Pradesh, India. AIDS 2005;19:611-9.

10. Colby DJ. HIV knowledge and risk factors among men who have sex with men in Ho Chi Minh City, Vietnam. J Acquir Immune Defic Syndr 2003;32:80-5

11. Feng JF, Lin HJ, Zhang YF, Qui DH, Wu QH, Shen WW. Investigation on the related knowledge, behaviour and infection of HIV/Syphilis among men who have sex with men in Taizhou city, China. Available from: http:// www.en.cnki.com.cn/Article_en/CJFDTOTAL-SHYI200811004.htm. [Last accessed on 2010 Dec 22; 14:24].

12. Bao YG, Zhang YH, Zhao JK, Sun JP, Tan HZ. HIV infection and KAP status among men who have sex with men in 14 Chinese cities. Zhonghua Yu Fang Yi Xue Za Zhi 2009;43:981-3.

13. Hui LI, Ying LI, Ya XI. A survey of the knowledge, attitude, and behaviors on STD/AIDS in men who have sex with men in Beijing. Available from: http://www.en.cnki.com.cn/Article_en/CJFDTOTAL-XBYA200504010. htm. [Last accessed on 2011 Oct 29; 16:05].

14. Gao-Feng CA, Qioa-Qin MA, Xiao-hong PA. HIV/AIDS Related knowledge, Attitude, Practice and HIV/STD Infection among MSM in Two Cities of Zhejiang Province. Available from: http://www.en.cnki.com.cn/ Article_en/CJFDTOTAL-ZGYC200806019.htm. [Last accessed on 2011 Dec 12].

How to cite this article: Patil $S$, Naik VA, Narasannavar $A B$, Banjade B, Shrestha A. Knowledge, attitude, and practice about HIVIAIDS among men who have sex with men in Belgaum: A crosssectional study. Int J Med Public Health 2015;5:24-8.

Source of Support: Nil, Conflict of Interest: None declared. 